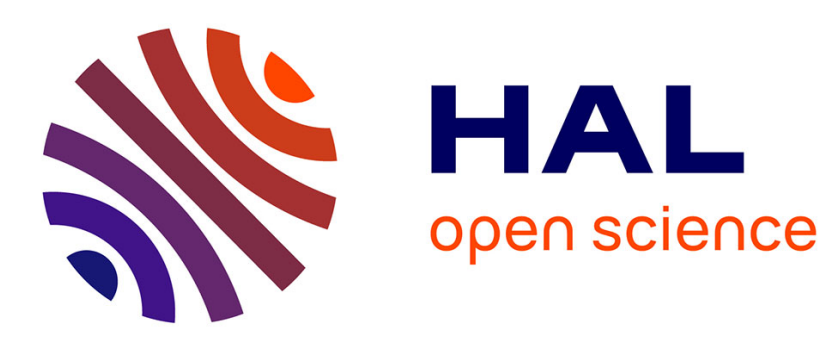

\title{
Characterisation of invasive group B streptococci from adults in Denmark 1999 to 2004
}

L. Lambertsen, K. Ekelund, I. C. Skovsted, A. Liboriussen, H.-C. Slotved

\section{To cite this version:}

L. Lambertsen, K. Ekelund, I. C. Skovsted, A. Liboriussen, H.-C. Slotved. Characterisation of invasive group B streptococci from adults in Denmark 1999 to 2004. European Journal of Clinical Microbiology and Infectious Diseases, 2010, 29 (9), pp.1071-1077. 10.1007/s10096-010-0941-z . hal-00612788

\section{HAL Id: hal-00612788 \\ https://hal.science/hal-00612788}

Submitted on 31 Jul 2011

HAL is a multi-disciplinary open access archive for the deposit and dissemination of scientific research documents, whether they are published or not. The documents may come from teaching and research institutions in France or abroad, or from public or private research centers.
L'archive ouverte pluridisciplinaire HAL, est destinée au dépôt et à la diffusion de documents scientifiques de niveau recherche, publiés ou non, émanant des établissements d'enseignement et de recherche français ou étrangers, des laboratoires publics ou privés. 
Diseases

Editorial Manager(tm) for European Journal of Clinical Microbiology \& Infectious

Manuscript Draft

Manuscript Number: EJCMID-D-09-00627R1

Title: Characterisation of invasive group B streptococci from adults in Denmark 1999 to 2004

Article Type: Article

Keywords: Streptococcus agalactiae; protein typing; $\mathrm{R} 4, \mathrm{C} \alpha, \mathrm{C} \beta$; $\mathrm{CPS}$ serotyping

Corresponding Author: Ph.D. Lotte Munch Lambertsen, Ph.D.

Corresponding Author's Institution: Statens Serum Institut

First Author: Lotte Munch Lambertsen, Ph.D.

Order of Authors: Lotte Munch Lambertsen, Ph.D.; Kim Ekelund, Ph.D.; Ian C Skovsted; Anders

Liboriussen; Hans-Christian Slotved, Ph.D.

Abstract: The aim of this study was to characterise the GBS isolates causing severe invasive infections in patients (>15 years) in Denmark from 1999 to 2004.

Methods: 411 invasive GBS isolates were phenotypically characterised by CPS serotype and protein C $\alpha$, $\mathrm{C} \beta$ and $\mathrm{R} 4$.

Results: The incidence of invasive GBS disease ranged from 2.2 to 3.2 per 100,000 adults in the study period, being highest among adults above 65 years of age. Diabetes was observed in $15 \%$ of the cases, $12 \%$ had alcohol abuse and $7 \%$ had cancer. Of all isolates $77 \%$ were CPS serotypes Ia, Ib, III or V. The surface proteins $\mathrm{C} \alpha$ or R4 were detected as the only protein in $57 \%$ of the GBS isolates. C $\beta$ was detected in $12 \%$ of the isolates, but always in combination with either $\mathrm{C} \alpha$ or both $\mathrm{C} \alpha$ and $\mathrm{R} 4$. Conclusions: The incidence of invasive GBS infections continued to increase in Denmark from 1999 to 2004. In that period, the overall case fatality was $14 \%$. The most prevalent CPS serotypes were serotypes III, Ia, V and Ib. The most prevalent surface protein was R4 when testing for R4, C $\alpha$, C $\beta$. There was no clear relation between the GBS phenotype and infections with fatal outcome.

Response to Reviewers: Ref.: MS. No. EJCMID-D-09-00627

Dear Editor,

Thank you very much for accepting our manuscript for review and for send-ing reviewers comments on: "Characterisation of invasive group B strepto-cocci from adults in Denmark 1999 to 2004".

Based on the comments from the reviewers we have revised our manuscript. In the revised manuscript the changes are inserted with Microsoft words track changes. These revisions are also specified below.

Reviewers' comments:

\#Reviewer \#1: The seasonal data do not appear to be significant - the authors should not speculate on insignificant data.\# 
Answer: We agree with reviewer and have therefore deleted figure 1 and only writ-ten in the text, that we observed a seasonal tendency (see page 6 . line 22-25 and page 10, line 10-12).

Because of this figrure numbers for the remaining two figures have been changed thoughout the manuscript.

\#Reviewer \#1:This is a major problem in the discussion of the mortality data - this database should be used to do a multivariate analysis of the associations - both clinical and serotype - that appear to predict mortality - the authors can then specu-late on any significant associations - at the moment the speculations seem to be based on \% differences which is inadequate.\#

Answer: The main focus of this study was typing of the invasive GBS isolates from adults in Denmark. Thus as we also had information on fatal or not fatal out-come of the GBS infection and some information on the patients clinical conditions we found it relevant to add this information even though that it is impossible to make statistical significant conclusions as the study is too small for this. However to make it clear for the reader, that the added clinical information is of limit character, we have added several sentences to the manuscript to emphasis this.

We have added the sentence on page 12 line 19-20: "however the number of isolates belonging to each CPS serotype from fatal cases was too low to make clear conclusions" and on page 13, line 2-3:

"however the number of isolates belonging to each protein serotype from fatal cases was too low to make clear conclusions".

We have also added a sentence on page 13, line 8-12: "We are aware that to be able to make statistically significant conclusions on the GBS isolate types from fatal cases and non-fatal cases a higher number of cases would be needed however in a small country like Denmark this can be difficult. We find it informative to report observations related to fatal out-come and pa-tients clinical conditions if that information is available even though some studies are small."

\#Reviewer \#1:The major difference in incidence by sex in younger adults is striking, but here again statistical analysis is needed to see if that difference is real.\#

Answer: We believe that the incidence of females is higher than males in younger adults due to the fact that some of these women have recently delivered, in-creasing the risk of getting an invasive GBS infection. Unfortunately we did not have proper registration on how many of the women it was.

We hope that our response has made the manuscript acceptable for publica-tion in your journal. 
2

${ }_{4}^{3} 2$ Running title: Characterisation of Danish invasive group B streptococci.

5

63

7

8 10

115

Division of Microbiology and Diagnostics, Statens Serum Institut, Artillerivej 5, DK-2300

Copenhagen S, Denmark

${ }^{2}$ SSI Diagnostica, Statens Serum Institut, Hillerød, Denmark

Present address:

DK-2300 Copenhagen S, Denmark

*Corresponding author Tel: +45 3268 3258, Fax: +45 3268 8129, E-mail: LLM@SSI.dk

\section{Characterisation of invasive group B streptococci from adults in Denmark 1999 to 2004}

Lambertsen, Lotte ${ }^{1 *}$, Ekelund, Kim ${ }^{1 \mathrm{a}}$, Skovsted, Ian. C. ${ }^{2}$, Liboriussen, Anders $^{2 \mathrm{~b}}$, H-C. Slotved ${ }^{1}$

${ }^{1}$ Neisseria and Streptococci Reference, Department of Bacteriology, Mycology and Parasitology,

${ }^{a}$ Hvidovre Hospital, Department of Anaesthesia , Kettegaard Allé 30, DK-2650 Hvidovre, Denmark

${ }^{\mathrm{b}}$ Department of Vaccine Development, Division of Vaccine, Statens Serum Institut, Artillerivej 5,

Lotte Lambertsen, Neisseria and Streptococci Reference, Department of Bacteriology, Mycology and Parasitology, Statens Serum Institut, Artillerivej 5, DK-2300 Copenhagen S, Denmark 


\section{Abstract}

The aim of this study was to characterise the GBS isolates causing severe invasive infections in patients (>15 years) in Denmark from 1999 to 2004.

Methods: 411 invasive GBS isolates were phenotypically characterised by CPS serotype and protein $\mathrm{C} \alpha, \mathrm{C} \beta$ and R4.

Results: The incidence of invasive GBS disease ranged from 2.2 to 3.2 per 100,000 adults in the study period, being highest among adults above 65 years of age. Diabetes was observed in $15 \%$ of the cases, $12 \%$ had alcohol abuse and $7 \%$ had cancer. Of all isolates $77 \%$ were CPS serotypes Ia, Ib, III or V. The surface proteins C $\alpha$ or R4 were detected as the only protein in $57 \%$ of the GBS isolates. $\mathrm{C} \beta$ was detected in $12 \%$ of the isolates, but always in combination with either $\mathrm{C} \alpha$ or both $\mathrm{C} \alpha$ and $\mathrm{R} 4$.

Conclusions: The incidence of invasive GBS infections continued to increase in Denmark from 1999 to 2004 . In that period, the overall case fatality was $14 \%$. The most prevalent CPS serotypes were serotypes III, Ia, V and Ib. The most prevalent surface protein was R4 when testing for R4, $\mathrm{C} \alpha, \mathrm{C} \beta$. There was no clear relation between the GBS phenotype and infections with fatal outcome.

Keyword: Streptococcus agalactiae, protein typing R4, C $\alpha, \mathrm{C} \beta, \mathrm{CPS}$ serotyping. 


\section{INTRODUCTION}

Invasive infections among non-pregnant adults caused by Streptococcus agalactiae, also known as Lancefield group B streptococci (GBS), is a well-known phenomenon [1][2].

The reported incidence of invasive GBS infections in adults varies from 3 to more than 20 per 100,000 persons, depending on age and health. The incidence is particularly high among the elderly above 65 years of age [3][1][4]. Henning et al [5] also found that there was a higher incidence of invasive disease with GBS infections among elderly residing in nursing homes compared to community residents. In particular elderly persons aged 65 years or more with an underlying medical disease seem to be at a higher risk of contracting invasive GBS infections than other adults. The underlying medical conditions and/or chronic diseases which seem to be most important in relation to invasive GBS infections were diabetes mellitus, neurologic diseases, cirrhosis or other liver diseases, stroke, breast cancer and renal failure [6][7][1][4]. In summary, adults at risk of getting a severe GBS infection seem to be adults with reduced immunesystems [4].

The case fatality rate of invasive GBS infections among adults varies from 5 to more than $15 \%$ depending on age [3][4][7]. Blancas et al [7] reported that $9.3 \%$ of patients admitted to a hospital in Barcelona, Spain, with a positive GBS blood culture died; it was found that the presence of shock and cancer were factors associated with risk of dying from the disease [7]. In 2005, Edwards and Bakers [8] reviewed the situation in the United States and found the case fatality rate among elderly to be estimated to $14.5 \%$. Per 100,000 persons, this case fatality rate was higher than the estimated case fatality rate due to group A streptococcal infections but lower than the estimate for pneumococcal infections [8].

In Denmark, a study on invasive infections caused by haemolytic streptococci in the period 1999 to 2002 showed that invasive infections due to GBS among non-pregnant adults had increased slightly during the last years, and that the incidence of invasive GBS infections was higher for elderly above 
1165 years than for younger adults. The case fatality rate was 19\% [6]. With a high incidence in

3 4

certain age groups and a relative high case fatality rate, invasive GBS infections are of high importance, and GBS is a bacterium which should be surveyed carefully.

GBS isolates can be phenotypically characterised based on surface components such as capsular polysaccharides (CPS) and surface proteins. Based on structural differences in polysaccharide capsules, GBS isolates can be divided into ten different serotypes: Ia, Ib, and II to IX [9]. A CPS serotyping method based on a precipitation reaction test, using serotype specific antisera against the capsules and hot acid extracts of the bacteria, has been used in many laboratories since it was introduced by Dr Lancefield in the 1930s. The phenotypic CPS serotype can also be determined using other methods such as GBS latex, ELISA or ouchterlony immuno-diffusion test [10][9]. Some isolates are not typeable using these methods and are, therefore, assigned NT. Another phenotypic characterisation method is to test for the presence of different GBS surface proteins [11][12]. Proteins, which in other studies have proven useful markers to test for are $\mathrm{C} \alpha, \mathrm{C} \beta$, $\mathrm{R}$, and Alp proteins [12][13][14]. Capsular polysaccharides as well as surface proteins are useful typing targets as they are the components recognised by the immune system and, therefore, also possible components of future vaccines [12][15].

The aim of this study was to characterise GBS isolates causing severe invasive infections in patients (>15 years) in Denmark from 1999 to 2004. Phenotypic characterisation methods were used to evaluate the CPS serotypes and protein profile distributions among the GBS isolates as well as to relate these results to infected patients, their age, sex and outcome of infection.

\section{Materials and Methods}

Clinical isolates and patient data 
11 A total of 411 invasive GBS isolates (from blood and cerebrospinal fluid) isolated from 1999 to

2004 from patients (> 15 years old) and received from the Danish departments of clinical microbiology laboratories were included in the study. Ekelund et al. (2005) [6] estimated for the period of 1999 to 2002 the proportion of all invasive GBS isolates sent in to be $58 \%$ percent. Only one isolate per patient was included in this study. All isolates were confirmed to be GBS by inspection of colony morphology on 5\% blood agar plates (SSI Diagnostica, Statens Serum Institut, Hillerød, Denmark) as well as with a group specific agglutination test using group B latex serum (Oxoid A/S, Greve, Denmark). All isolates were stored at $-80^{\circ} \mathrm{C}$ in nutrient beef broth containing $10 \%$ glycerol (SSI Diagnostica).

All patient data used in this study was approved by the Scientific-Ethical Committees for Copenhagen and Frederiksberg (no. (KF) 11-156/00) and by the Danish Data Protection Agency (no. 2001-41-0807). Patient data was obtained using a questionnaire filled in by the clinician.

\section{CPS serotyping}

The majority of the isolates were serotyped with GBS latex agglutination test (SSI Diagnostica), and all isolates were serotyped/confirmed using the capillary precipitation method (Lancefield method) [16][10]. The capillary precipitation method was performed using serotype specific GBS antisera (Ia - IX) (SSI Diagnostica) and capsular antigens extracted with both 0.1 and $0.2 \mathrm{~N} \mathrm{HCl}$ (Lancefield extraction method). The latex agglutination test was performed as recommended by the manufacturer (SSI Diagnostica). Non-serotypeable isolates were designated NT.

\section{Surface protein antigen detection $(\mathrm{C} \alpha, \mathrm{C} \beta$ and $\mathrm{R} 4)$}

$\mathrm{C} \alpha, \mathrm{C} \beta$ and R4 (also named Rib [17]) specific polyclonal rabbit antisera (SSI Diagnostica) were used to detect surface proteins using a western blot procedure previously described by Slotved et al 
11 [9]. Briefly, GBS was grown in Todd Hewitt broth overnight at $36^{\circ} \mathrm{C}$ and $5 \% \mathrm{CO}_{2}$. The bacterial

3 4

culture was mixed with NuPAGE sample buffer (Invitrogen, Carlsbad, CA) and NuPAGE reducing agent (Invitrogen) and heated for $10 \mathrm{~min}$ at $70^{\circ} \mathrm{C}$. Ten microliters of sample mixture was loaded on a gel (Tris-Bis 4-12\% gradient gel, NuPAGE, Invitrogen) and the gel was run for $1 \mathrm{~h}$ at $180 \mathrm{~V}$ with NuPAGE running buffer (Invitrogen) on the electrophoresis apparatus XCell4 Surelock Midi-Cell (Invitrogen). After electrophoresis, the proteins were transferred to a nitrocellulose membrane (Invitrogen). The membrane was incubated in blocking buffer (50 g skimmed milk powder (Matas A/S, Allerød, Denmark) added to 1L washing buffer (1×PBS with $0.05 \%$ Tween 20$)$ (SSI

Diagnostica)). Anti $\mathrm{C} \alpha$, $-\mathrm{C} \beta$ or -R4 polyclonal rabbit sera (SSI Diagnostica) were used as primary antibodies (diluted 1:200), and alkaline phosphatase-conjugated goat anti-rabbit immunoglobulin G (Sigma Aldrich, St. Louis, MO) was diluted 1:1000 and used as the secondary antibody. 5-bromo-4chloro-3-indolylphosphate nitro blue tetrazolium (Sigma) was used as a substrate for the colour reaction, which was stopped by the addition of MQ water.

\section{RESULTS}

Incidence and seasonal variation of invasive GBS

During the six years from 1999 to 2004, the incidence per 100,000 adults (calculated on the basis of the number of received isolates per 100,000 persons above 15 years) increased slightly from 1.3 in 1999 to 1.7 in 2004 with at maximum of 1.9 in 2002 . Based on an estimated proportion of invasive isolates of 58\% [6] as described in Materials and Methods, the incidence of invasive GBS infections in Denmark ranged from 2.2 to 3.2 per 100,000 adults in the study period.

The seasonal distribution of invasive GBS isolates per year showed large variation with . However, there was-a tendency that a higher number of invasive GBS infections were registered in the four months from August to November, compared with the rest of the year-Fig. 1). 
Age and sex dependent incidence, case fatality and underlying medical condition

The GBS isolates were from patients with a mean age of 62.8 years ranging from 16 to 99 years of age; $53 \%(\mathrm{n}=219)$ were females. In the study, we received information on $96 \%$ of the patients concerning outcome of invasive GBS infection and underlying medical condition. The overall case fatality was estimated to be $14 \%(\mathrm{n}=58)$. Of these 58 cases with fatal outcome, $51.7 \%$ were males. In the age group below 40 years, 50 isolates were obtained from females and 12 isolates were from males i.e. the age dependent incidence of invasive GBS infections was 1.1 for females and 0.2 for males. The case fatality in this age group was $5.2 \%$ for females and $7.7 \%$ for males (Fig. 21 ). In contrast, for the age group above 65 years the number of isolates received was 83 isolates from males and 94 isolates from females with a corresponding incidence of invasive GBS infections of 5.7 for males and 3.6 for females. The case fatality in this age group was $17 \%$ for both males and females (Fig. Z1 ). As to underlying medical conditions, diabetes was observed in 15\% of the cases with a GBS infection, $12 \%$ had an alcohol abuse and 7\% had cancer. Furthermore, 7\% had had a recent operation and 7\% had recently delivered (data not shown).

CPS serotype and protein distribution of all isolates

Of all GBS isolates, $77 \%$ were tested to be CPS serotype III ( $\mathrm{n}=121)$, Ia (81), V (77), or Ib (38) (Fig. 32a). No isolates of CPS serotypes VI or VII were found among the received isolates. However, among the 2004 isolates, one isolate of the recently defined CPS serotype IX was found. A total of $11 \%$ of the isolates were NT with no CPS serotype detected (Fig. 32a).

The isolates were also tested phenotypically for the presence of the three surface proteins $C \alpha, C \beta$, and R4. The surface proteins C $\alpha$ or R4 were detected as the only protein in 57\% of the GBS isolates (Fig. 32 b), while $\mathrm{C} \beta$ was detected in $12 \%$ of the isolates, but always in combination with either $\mathrm{C} \alpha$ 
11 or both $\mathrm{C} \alpha$ and R4. In $22 \%$ of the isolates, none of the three surface proteins were detected (Fig.

3

4 63 7 32 b).

Upon combining the CPS serotyping results with the protein typing results, phenotype III-R4 was found to be the most dominant combination with $18 \%$ of all isolates. Twelve percent of the isolates were typed to be phenotype Ia-C $\alpha$ and $11 \%$ were phenotype V-R4 (Fig. 3c). Within CPS serotype III isolates, R4 was detected as the only protein in $62 \%$ of the isolates; among CPS serotype Ia isolates, $\mathrm{C} \alpha$ was detected as the only protein in $60 \%$ of the isolates and among CPS serotype V, $58 \%$ tested positive for protein R4 (Fig. 32 c).

During the six years of the study period, CPS serotype III was the dominating type each year except for 2002, when serotype Ia isolates were present in a higher number (data not shown). CPS serotype V was observed to increase in number over the period from 1999 - 2004. During the six years, the protein serotype R4 was detected in most isolates per year except for 2002, when protein type C $\alpha$ was detected in most isolates (data not shown). In the year 2004, protein R4 was detected in a large number of isolates. Upon combining both typing methods, the high number of R4 protein was explained by a high number of isolates with phenotypes III-R4 and V-R4.

CPS serotype and protein distribution of isolates from cases with fatal outcome

Of GBS isolates from cases with a fatal outcome, $69 \%$ were tested to be CPS serotype III $(n=16)$, Ia (12) or V (12) (Fig. 3d) and 7\% of the isolates were NT with no CPS serotype detected (Fig. 32d). The surface proteins $\mathrm{C} \alpha$ or R4 were detected as the only protein in 53\% of the GBS isolates from fatal cases, while $\mathrm{C} \beta$ was detected in $12 \%$ of the isolates, but always in combination with both $\mathrm{C} \alpha$ and R4 (Fig. 32e). In 24\% of the isolates, none of the three surface proteins were detected (Fig. 32e). When combining the CPS serotyping results with the protein typing results, $26 \%$ of the isolates from fatal cases were tested to have phenotypes III-R4 or V-R4 (Fig. 32ff). 
11 The case fatality based on the infecting CPS serotype varied from $0 \%$ to $28.6 \%$, none of all patients

infected with serotype IX had fatal outcome, $8.9 \%$ of all patients infected with an NT and $28.6 \%$ of all patients infected with CPS serotype VIII (data not shown). In addition, the case fatality seemed to be related to the sex of the infected patient (data not shown); i.e., $83.3 \%(\mathrm{~N} \underline{n}=12)$ of all cases with a fatal outcome and infected with a CPS serotype Ia, were women, $62.5 \%(\mathrm{~A} n=16)$ of all cases with a fatal outcome and infected with a CPS serotype III were women whereas $66.7 \%(\mathrm{~N} \underline{n}=12)$ of all cases with a fatal outcome and infected with a CPS serotype V were men (data not shown); however, the number of isolates in each group was low.

\section{DISCUSSION}

This study presents data on invasive GBS isolates from patients (>15 years) in the period from 1999 to 2004 in Denmark. The overall incidence of invasive GBS infection in adults in the study period was found to increase slightly from 1.3 per 100,000 adults in 1999 to 1.7 in 2004 . Based upon this, only approximately $58 \%$ of all GBS isolates identified were received [6], the estimated incidence in the period ranged from 2.2 to 3.2 per 100,000 adults. However, the true incidence of GBS was probably higher as this estimate did not take into account cases where viable isolates were not cultured or detected due to for example treatment with antibiotics prior to diagnostic culturing. Comparing these data with similar data from an earlier time period 1988 to 2002 but from the same geographic area presented in the study by Ekelund et al [6], the incidence has slowly increased in Denmark from 1988 with an incidence below 0.5 per 100,000 inhabitants until 2004 with an incidence of 2.9 per 100,000 adults. A similar incidence and increase in the incidence of invasive GBS has been observed in our neighbouring countries. In Sweden, an annual incidence of 2.4 per 100,000 inhabitants in the period 1999-2001 was found on invasive GBS infections. However, this includes the age group below 15 years of age [18]. In Norway, an average incidence in the age 
group above 19 years of age were found to be 1.34 in 1996-1998 rising to 3.1 per 100,000 in 19992006 [13]. Data on the incidence of invasive GBS infections from other parts of the world show, however, a higher incidence. In a study from USA, it was found that the incidence in the age group above 18 years increased from 3.6 cases per 100,000 persons in 1990 to 7.3 in 2007 [1]. In another study from USA, the overall incidence of invasive GBS in adults was found to be 6.0 per 100,000 persons in 1999 and 7.9 in 2005 [4]. In conclusion, the incidence of invasive GBS infections in adults seems to be increasing not only in Denmark but in several countries.

Looking at the seasonal variation-(Fig. 1), there was a tendency that a higher number of invasive GBS infections was registered in late summer and autumn compared to the rest of the year, thus the number of isolates per month per year was low. This observation is however similar to the observation in the study performed by Phares et al [4], in which they observed a seasonal variability with distinct peaks occurring each year during the later summer months. The reasen for this is unclear, but the observation may provide information which may be helpful in finding out why the incidence of invasive GBS infections is increasing.

Elderly patients (>65 years) was the age group with the highest incidence of invasive GBS infection; as to sex dependent incidence in this age group males had a higher incidence of invasive GBS compared to females (Figure $2 \underline{1}$ ). This is consistent with other studies finding that incidence of invasive GBS increases with age [13][4][1] and that a higher proportion of invasive isolates were from males [1]. The most common underlying medical condition of patients with invasive GBS infection observed in this study was diabetes (15\%), alcohol abuse (12\%) and cancer (7\%). Finding that a specific medical condition can be a possible risk factor for obtaining an invasive GBS infection has also been observed in similar but much larger studies. Skoff et al [1] found that $44 \%$ of the adults with an invasive GBS infection had diabetes, $15 \%$ had cancer and $7 \%$ of the cases had 
an alcohol misuse and Phares et al [4] found that $41 \%$ of cases with invasive GBS infection had diabetes and $17 \%$ cancer. The case fatality in this study was $14 \%$ which is within the rates found in other recent studies [4][3][8].

The majority of the 411 GBS isolates found in this study were tested to be serotype III (29.4\%), Ia (19.7\%), V (18.7\%) and Ib (9.2\%) of which serotype III was the most prevalent type (Fig. 32a). Comparing our GBS serotype distribution with a study from another Nordic country (Norway), including 465 GBS isolates from persons above 1 year of age in the period of 1996-2005, showed a similar distribution with the majority GBS isolates tested to be serotype III (24.4\%), V (24.1\%), Ib (15.1\%) and Ia (14.6\%) [13]. In Sweden, a smaller study testing 111 isolates from adults in 19982001 found $42 \%$ serotype V and 25\% III. Looking at studies performed geographically further away from Denmark, Phares et al [4] tested 4987 isolates collected from nonpregnant paediatric and adult cases in the period of 1999-2005 in USA. They found that the majority of the GBS isolates were serotypes V (31\%), Ia (24\%), II (12\%) and III (12\%). Skoff et al [1] performed a similar study testing 1933 isolates collected from nonpregnant adult cases in the period of 2005-2006 in USA, and found that the majority isolates were serotypes V (29.2\%), Ia (24.3\%), II (13.4\%) and III (11.4\%). Edwards and Baker [8] presented data on 589 invasive isolates from nonpregnant adults from USA in the period 1992-1999, in which the majority of the 589 tested GBS isolates were serotypes V (27.2\%), Ia (24.3\%), III (16.5\%), Ib (12.2) and II (11.9\%). In the three studies from USA the most prevalent serotype were found to be serotype V, compared to serotype III in two of three Nordic studies. Finally, a study by Lachenauer et al [19] showed that in Japan serotypes VIII and VI were very dominant, although this was colonizing isolates from pregnant women in Japan. The observed differences in dominating GBS serotypes in different geographic areas around the world and in different time periods show that a possible future effective global GBS vaccine needs 
to cover a high number of the serotypes, a fact also concluded by Maione et al. [20]. Another solution to limiting the number of included serotypes is to include a relevant protein component in the vaccine.

In this study, the prevalence of three proteins $(\mathrm{C} \alpha, \mathrm{C} \beta$ and $\mathrm{R} 4)$ and distribution within each serotype were tested on the invasive GBS isolates (Fig. 3). Our data showed that the R4 protein was the most prevalent among isolates and associated particularly with serotypes III and V whereas C $\alpha$ was found in isolates with serotype Ia. $\mathrm{C} \alpha$ and $\mathrm{C} \beta$ were often found in serotype Ib isolates (Fig. 32). In other studies [13][14], similar patterns and relations between proteins and serotypes have been found. However, as also seen in other studies [13][14], the data presented here showed that it was possible to find the three proteins in isolates of almost all known GBS serotypes (Fig. 32). Looking at the protein data from a vaccine point of view, this study supports the view of for example Persson et al [14] proposing the $\mathrm{R} 4$ protein in a conjugated vaccine with polysaccharide from several of the serotypes to be an ideal possible vaccine formulation.

Studies like this estimating the prevalence of serotypes and protein profiles of isolates from different parts of the world are needed to estimate the effectiveness of possible future vaccine formulations. A major goal of a possible vaccine would be to prevent invasive GBS infections and thus also fatal outcomes of the infection. It has been speculated that GBS isolates with certain CPS serotypes or proteins profiles would be related to fatal outcome. In this study we found the serotype distribution of isolates from cases with fatal outcome to be approximately the same as for all analysed isolates (Fig. 32d), however the number of isolates belonging to each CPS serotype from fatal cases was too low to make clear conclusions. For the protein serotype distribution of isolates from cases with fatal outcome, no isolates with both $C \alpha$ and $C \beta$ proteins were found (Fig. 32e). In contrast, a higher proportion of isolates with protein serotypes $\mathrm{C} \alpha, \mathrm{C} \beta, \mathrm{R} 4$ (12\% compared to $6 \%$ ) and $\mathrm{C} \alpha, \mathrm{R} 4$ (10\% compared to 6\%) from cases with fatal outcome (Fig. 32e) was detected 
compared to GBS isolates from cases surviving the GBS infection (Fig. 32 b). Apart from this, the protein serotype distribution of the isolates from cases with fatal outcome was approximately the same as among isolates from all analysed isolates, however the number of isolates belonging to each protein serotype from fatal cases was too low to make clear conclusions. When combining both CPS and protein typing results, the number of each phenotype was far too low for making $\underline{\text { clear }}$ conclusions (Fig. 32f). In conclusion, taking into account the low number of isolates from fatal cases, there was a tendency that similar patterns with regard to CPS serotype, proteins profile, and sex distribution were observed for isolates from fatal cases and all analysed isolates. This was also observed by Phares et al 2008 [4]. We are aware that to be able to make statistically significant conclusions on the GBS isolate types from fatal cases and from non-fatal cases a higher number of cases would be needed however in a small country like Denmark this can be difficult. Anyhow, we $\underline{\text { still find it informative to report observations related to fatal out-come and patients clinical }}$ conditions if that information is available even though some studies are small.

The overall conclusions from this study are that in Denmark from 1999 to 2004, the incidence of invasive GBS infections in adults, and in particular in elderly adults continued to increase, and the case fatality was $14 \%$. The most prevalent CPS serotypes were serotypes III, Ia, V and Ib and the most prevalent surface protein was $\mathrm{R} 4$ when testing for $\mathrm{R} 4, \mathrm{C} \alpha, \mathrm{C} \beta$. There was no clear relation between the GBS phenotype and cases with fatal outcome.

\section{ACKNOWLEDGEMENTS}

We thank the Danish departments of clinical microbiology for sending isolates to the National Neisseria and Streptococcus Reference Center. Clinicians are also thanked for using time on filling 
11 in questionnaires with care. The laboratory staff is thanked for their technical expertise and ever

2

${ }_{4}^{3} 2$ positive commitment to the work. This work is a part of the National Surveillance of severe

63 streptococcal infections.

7

84

10

11

12

13

14

15

16

17

18

19

20

21

22

23

24

25

26

27

28

29

30

31

32

33

34

35

36

37

38

39

40

41

42

43

44

45

46

47

48

49

50

51

52

53

54

55

56

57

58

59

60

61

62

63 
Fig. 1. Average numbers of invasive GBS isolates per month for six years, from 1999 to 2004 in Denmark $(\mathrm{N}=411)$.

Fig. 21. Age related incidence of invasive GBS per 100,000 persons (left Y-axis) and number of invasive GBS isolates per age group from non-fatal cases and fatal cases (right $\mathrm{Y}$-axis) $(\mathbb{N} \underline{n}=411)$.

Fig. 32a) CPS serotype distribution of invasive GBS isolates from all cases, Denmark 1999 to 2004 $(\underline{N} \underline{n}=411)$. 32 $\underline{b})$ Protein distribution of invasive GBS isolates from all cases, Denmark 1999 to $2004(\underline{N} \underline{n}=411)$. 32 $\mathbf{c})$ Combined CPS serotype and protein profile of invasive GBS isolates from all cases, Denmark 1999 to $2004(\underline{N} \underline{n}=411)$. 32 d) CPS serotype distribution of invasive GBS isolates from cases with fatal outcome, Denmark 1999 to $2004(\underline{\underline{n}}=58)$. 32e $)$ Protein distribution of invasive GBS isolates from cases with fatal outcome, Denmark 1999 to 2004 ( $\mathrm{N} \underline{n}=58)$. 32f $)$ Combined CPS serotype and protein profile of invasive GBS isolates from cases with fatal outcome, Denmark 1999 to $2004(\underline{\mathrm{N}} \underline{\mathrm{n}}=58)$. 


\section{References}

1. Skoff,TH, Farley, M. M., Petit, S., Craig, A. S., Schaffner, W., Gershman, K., Harrison, L. H., Lynfield, R., Mohle-Boetani, J., Zansky, S., Albanese, B. A., Stefonek, K., Zell, E. R., Jackson, D., Thompson, T., Schrag, S. J. (2009) Increasing burden of invasive group B streptococcal disease in nonpregnant adults, 1990-2007 Clin.Infect.Dis. 49:85-92.

2. Zhao,Z, Kong, F., Zeng, X., Gidding, H. F., Morgan, J., Gilbert, G. L. (2008) Distribution of genotypes and antibiotic resistance genes among invasive Streptococcus agalactiae (group B streptococcus) isolates from Australasian patients belonging to different age groups Clin.Microbiol.Infect. 14:260-267.

3. Schrag,SJ, Zywicki, S., Farley, M. M., Reingold, A. L., Harrison, L. H., Lefkowitz, L. B., Hadler, J. L., Danila, R., Cieslak, P. R., Schuchat, A. (2000) Group B streptococcal disease in the era of intrapartum antibiotic prophylaxis N.Engl.J.Med. 342:15-20.

4. Phares,CR, Lynfield, R., Farley, M. M., Mohle-Boetani, J., Harrison, L. H., Petit, S., Craig, A. S., Schaffner, W., Zansky, S. M., Gershman, K., Stefonek, K. R., Albanese, B. A., Zell, E. R., Schuchat, A., Schrag, S. J. (2008) Epidemiology of invasive group B streptococcal disease in the United States, 1999-2005 JAMA 299:2056-2065.

5. Henning,KJ, Hall, E. L., Dwyer, D. M., Billmann, L., Schuchat, A., Johnson, J. A., Harrison, L. H. (2001) Invasive group B streptococcal disease in Maryland nursing home residents J.Infect.Dis. 183:1138-1142.

6. Ekelund,K, Skinhoj, P., Madsen, J., Konradsen, H. B. (2005) Invasive group A, B, C and G streptococcal infections in Denmark 1999-2002: epidemiological and clinical aspects 8 Clin.Microbiol.Infect. 11:569-576. 

27 28

7. Blancas,D, Santin, M., Olmo, M., Alcaide, F., Carratala, J., Gudiol, F. (2004) Group B streptococcal disease in nonpregnant adults: incidence, clinical characteristics, and outcome

3 Eur.J.Clin.Microbiol.Infect.Dis. 23:168-173.

8. Edwards,MS, Baker, C. J. (2005) Group B streptococcal infections in elderly adults 5 Clin.Infect.Dis. 41:839-847.

9. Slotved,HC, Kong, F., Lambertsen, L., Sauer, S., Gilbert, G. L. (2007) Serotype IX, a Proposed New Streptococcus agalactiae Serotype

4 J.Clin.Microbiol. 45:2929-2936.

10. Slotved,HC, Elliott, J., Thompson, T., Konradsen, H. B. (2003) Latex assay for serotyping of group B Streptococcus isolates

9 J.Clin.Microbiol. 41:4445-4447.

11. Moyo,SR, Maeland, J. A., Bergh, K. (2002) Typing of human isolates of Streptococcus agalactiae (group B streptococcus, GBS) strains from Zimbabwe 5 J.Med.Microbiol. 51:595-600.

12. Lindahl,G, Stalhammar-Carlemalm, M., Areschoug, T. (2005) Surface proteins of Streptococcus agalactiae and related proteins in other bacterial pathogens Clin.Microbiol.Rev. 18:102-127.

13. Bergseng,H, Rygg, M., Bevanger, L., Bergh, K. (2008) Invasive group B streptococcus (GBS) disease in Norway 1996-2006 3 Eur.J.Clin.Microbiol.Infect.Dis. 27:1193-1199. 
14. Persson,E, Berg, S., Bevanger, L., Bergh, K., Valso-Lyng, R., Trollfors, B. (2008)

Characterisation of invasive group B streptococci based on investigation of surface proteins and genes encoding surface proteins

3 Clin.Microbiol.Infect. 14:66-73.

15. Johri,AK, Paoletti, L. C., Glaser, P., Dua, M., Sharma, P. K., Grandi, G., Rappuoli, R. (2006) Group B Streptococcus: global incidence and vaccine development 1 Nat.Rev.Microbiol. 4:932-942.

16. Slotved,HC, Sauer, S., Konradsen, H. B. (2002) False-negative results in typing of group B streptococci by the standard lancefield antigen extraction method J.Clin.Microbiol. 40:1882-1883.

17. Smith,BL, Flores, A., Dechaine, J., Krepela, J., Bergdall, A., Ferrieri, P. (2004) Gene encoding the group B streptococcal protein R4, its presence in clinical reference laboratory isolates \& R4 protein pepsin sensitivity 8 Indian J.Med.Res. 119 Suppl:213-220.

18. Persson,E, Berg, S., Trollfors, B., Larsson, P., Ek, E., Backhaus, E., Claesson, B. E., Jonsson, L., Radberg, G., Ripa, T., Johansson, S. (2004) Serotypes and clinical manifestations of invasive group B streptococcal infections in western Sweden 1998-2001 1 Clin.Microbiol.Infect. 10:791-796.

19. Lachenauer,CS, Kasper, D. L., Shimada, J., Ichiman, Y., Ohtsuka, H., Kaku, M., Paoletti, L. C., Ferrieri, P., Madoff, L. C. (1999) Serotypes VI and VIII predominate among group B streptococci isolated from pregnant Japanese women 1 J.Infect.Dis. 179:1030-1033. 
11 20. Maione,D, Margarit, I., Rinaudo, C. D., Masignani, V., Mora, M., Scarselli, M., Tettelin, H.,

32

5

63

7

${ }_{9}^{8} 4$ 10
Brettoni, C., Iacobini, E. T., Rosini, R., D'Agostino, N., Miorin, L., Buccato, S., Mariani, M., Galli, G., Nogarotto, R., Nardi, Dei, V, Vegni, F., Fraser, C., Mancuso, G., Teti, G., Madoff, L. C., Paoletti, L. C., Rappuoli, R., Kasper, D. L., Telford, J. L., Grandi, G. (2005) Identification of a universal Group B streptococcus vaccine by multiple genome screen

3 Science 309:148-150. 


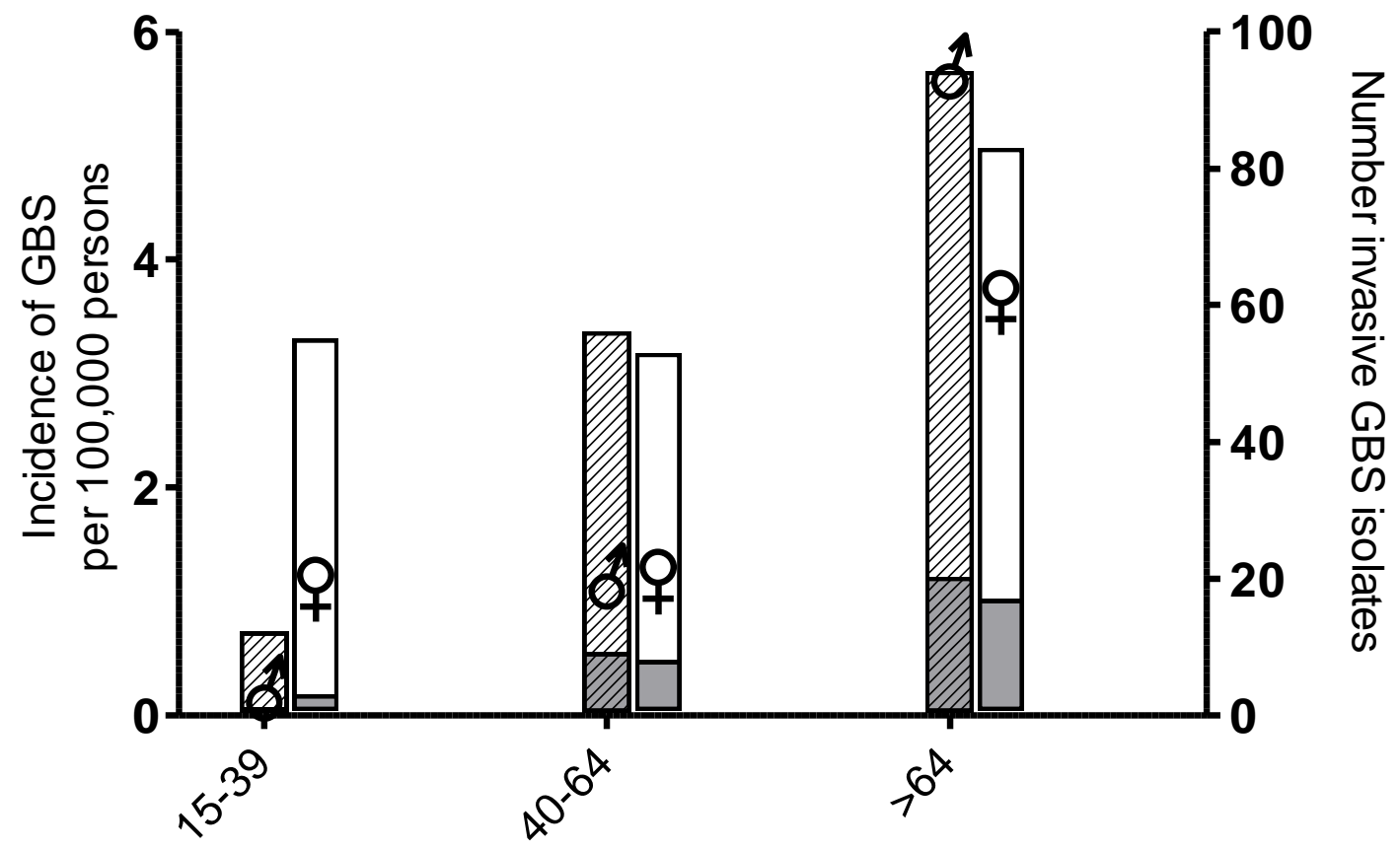

Age group (years)

q incidence, female $\mathbb{Z}$ non-fatal cases male $\mathbb{Z}$ fatal cases, male $\boldsymbol{\delta}$ incidence, male $\square$ non-fatal case, female $\square$ fatal case, female 

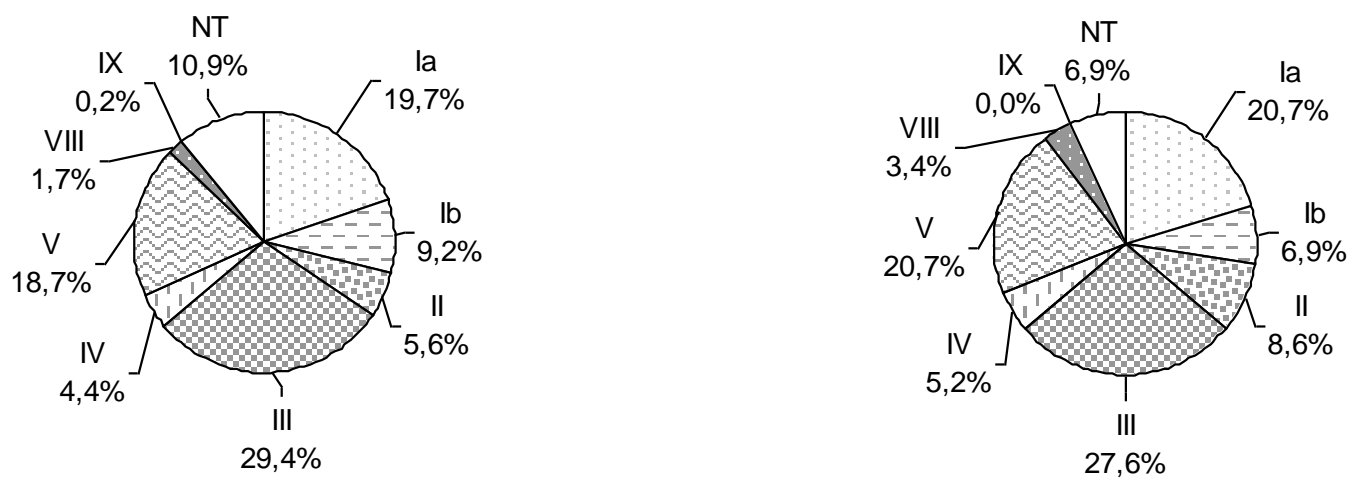

$2 b$

$2 e$
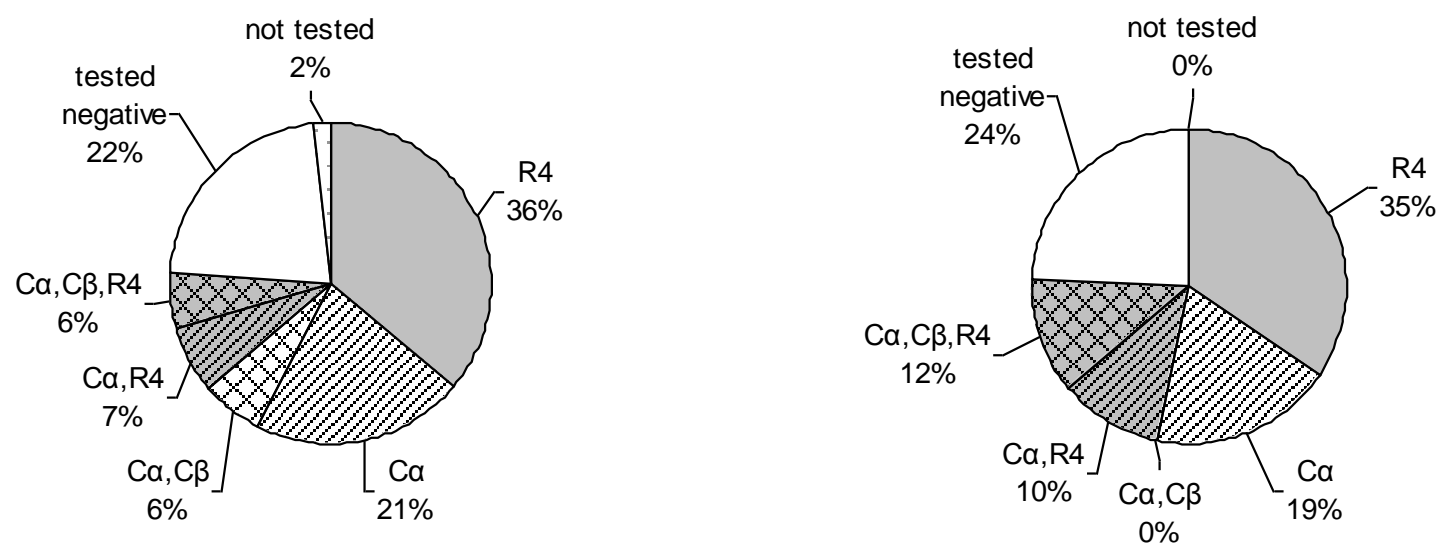

2c

\section{$2 f$}
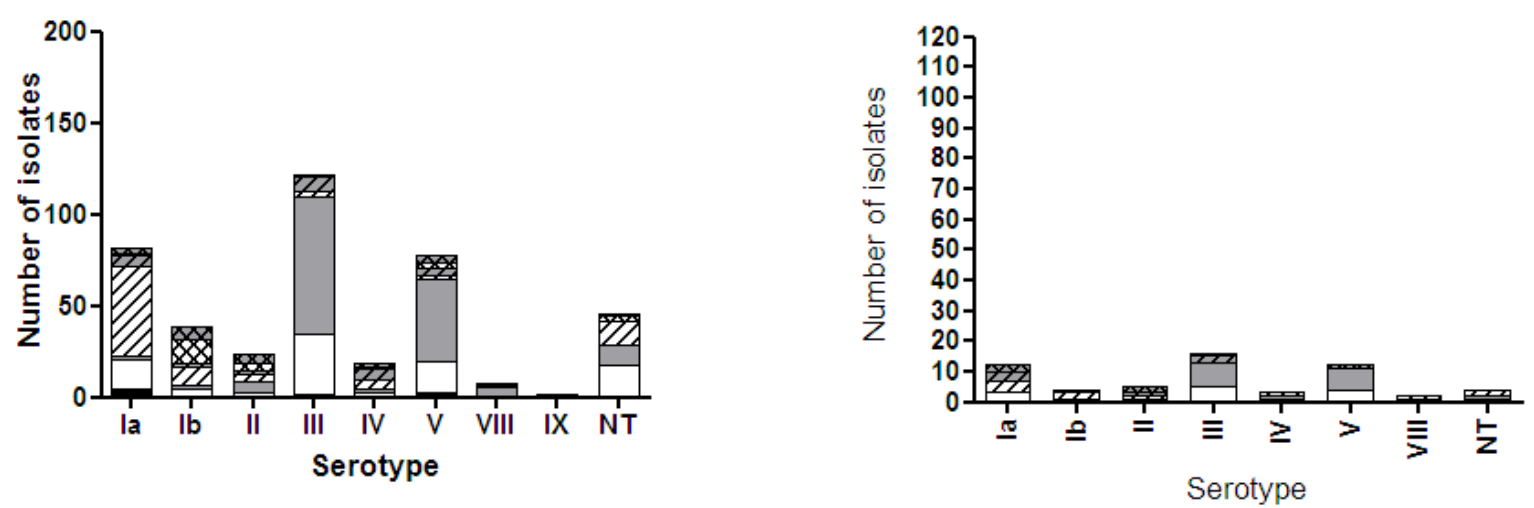

V7 $\mathrm{C} \alpha \mathrm{C} \alpha, \mathrm{C} \beta \quad \mathrm{C} \alpha, \mathrm{C} \beta, \mathrm{R} 4$ R4 D/2 Ca, R4

not tested $\square$ tested negativ

VI $\mathrm{C} \alpha \mathrm{V} \mathrm{C} \alpha, \mathrm{R} 4 \Longleftrightarrow \mathrm{C} \alpha, \mathrm{C} \beta, \mathrm{R} 4$ tested negativ R4 
Our ref.

9 March 201010

\section{European Journal of Clinical Microbiology \& Infectious Diseases}

Ref.: MS. No. EJCMID-D-09-00627

Dear Editor,

Thank you very much for accepting our manuscript for review and for sending reviewers comments on: "Characterisation of invasive group B streptococci from adults in Denmark 1999 to 2004".

Based on the comments from the reviewers we have revised our manuscript. In the revised manuscript the changes are inserted with Microsoft words track changes. These revisions are also specified below.

Reviewers' comments:

Reviewer \#1: The seasonal data do not appear to be significant - the authors should not speculate on insignificant data.

We agree with reviewer and have therefore deleted figure 1 and only written in the text, that we observed a seasonal tendency (see page 6. line 22-25 and page 10, line 10-12).

Because of this figrure numbers for the remaining two figures have been changed thoughout the manuscript.

This is a major problem in the discussion of the mortality data - this database should be used to do a multivariate analysis of the associations - both clinical and serotype - that appear to predict mortality - the authors can then speculate on any significant associations - at the moment the speculations seem to be based on \% differences which is inadequate.

The main focus of this study was typing of the invasive GBS isolates from adults in Denmark. Thus as we also had information on fatal or not fatal outcome of the GBS infection and some information on the patients clinical conditions we found it relevant to add this information even though that it is impossible to make statistical significant conclusions as the study is too small for this.

However to make it clear for the reader, that the added clinical information is of limit character, we have added several sentences to the manuscript to emphasis this.

We have added the sentence on page 12 line 19-20: "however the number of isolates belonging to each CPS serotype from fatal cases was too low to make clear conclusions" and on page 13, line 2-3: "however the number of isolates belonging to each protein serotype from fatal cases was too low to make clear conclusions". 
We have also added a sentence on page 13, line 8-12: "We are aware that to be able to make statistically significant conclusions on the GBS isolate types from fatal cases and non-fatal cases a higher number of cases would be needed however in a small country like Denmark this can be difficult. We find it informative to report observations related to fatal out-come and patients clinical conditions if that information is available even though some studies are small."

The major difference in incidence by sex in younger adults is striking, but here again statistical analysis is needed to see if that difference is real.

We believe that the incidence of females is higher than males in younger adults due to the fact that some of these women have recently delivered, increasing the risk of getting an invasive GBS infection. Unfortunately we did not have proper registration on how many of the women it was.

We hope that our response has made the manuscript acceptable for publication in your journal.

Yours sincerely,

Lotte Lambertsen, PhD

Neisseria and Streptococcus Reference Center

Department for Bacteriology, Mycology and Parasitology,

Tel: +4532683258

Fax: +4532688238

IIm@ssi.dk 